\title{
Giant pedunculated colonic lipoma causing colo- colic intussusception and a rectal bleeding
}

\begin{abstract}
Intussusception is less common in adults than in children. Intussusception in adults is associated with an identifiable etiology in $90 \%$ of cases. Lipoma of the large intestine is rare; with a reported incidence ranging between $0.2 \%$ and $4.4 \%$. Small Lipomas are usually asymptomatic, but giant Lipomas are often presented as abdominal pain, vomiting, diarrhea, bleeding and Intussusception. We present a case of 45-year-old man in our emergency room with intermittent abdominal cramps, rectal bleeding for eight days. Physical examination showed tenderness in the left lower abdominal quadrant. Blood found in rectal examination. Colonoscopy in two periods revealed an ulcerative mass in the proximal of descending colon. A CT scan showed a coil spring appearance highly suspicious for Intussusception of the descending-colon, a laparotomy was performed. The Intussusception was found in the descending colon, with extended left hemicolectomy, en-bloc resection was performed with end-to-end anastomosis. After surgical resection, the histo pathologic examination of the specimen showed the configuration of pedunculatedlipoma with tip ulceration, measuring $9 \times 5 \times 6 \mathrm{~cm}$ in diameter. Patient discharged on day five post-operative with good condition.
\end{abstract}

Volume 2 Issue I - 2015

\author{
Manouchehr Aghajanzadeh \\ Inflammatory Lung Disease Research Center, Guilan University \\ of Medical Sciences, Iran
}

Correspondence: Manouchehr Aghajanzadeh, Inflammatory Lung Disease Research Center, Guilan University of Medical Sciences, Rasht Sardar Jangal Avenue, Razi hospital, Iran, Tel 9117656035,Email massahnias@yahoo.com

Received: January 3I, 20I5 | Published: April I, 2015

Keywords: colonic lipoma, intussusception, colonoscopy, hemicolectomy, en-bloc resection

\section{Introduction}

Intussusceptions are a rare cause of bowel obstruction that accounting $1 \%$ in adults and ileocolic valve is the most part of small bowel that involved. ${ }^{1}$ Colo colonic Intussusception accounts for $17 \%$ of confirmed intussusceptions in the literatures. ${ }^{2}$ Lymphoma and adenocarcinoma are the most leading points of Intussusception (63\%) as malignant lesions. ${ }^{3}$ One of the several sub mucosal tumors is colonic Lipoma that rarely encountered in clinical practice. ${ }^{1}$ If complications of colonic lipoma such as obstruction, intussusceptions, perforation or massive hemorrhage present in patients, surgical removal of tumor is indicated. ${ }^{3,4}$ Different symptoms and presentations of colonic Lipoma in patients made it as a significant challenge in radiological confirmation and management. ${ }^{3-5}$ Here we present a 45 years old man who presented with sub-acute obstruction and rectal bleeding secondary to colo-colonic Intussusception due to a Lipoma at the splenic flexure of colon.

\section{Case report}

A 45 year old male patient admitted in surgical ward that complained intermittent epi gastric and left lower quadrant abdominal pain accompanied with nausea and vomiting. He has no history of medical or surgical problem. He mentioned about weight loss, moderately rectal bleeding and changing in bowel habits. In abdominal physical examination, mild tenderness over the left abdomen has been detected. Subsequent gastro endoscopy was normal. Colonoscopy was performed and find out a huge ulcerative lesion in the descending colon and pathologist reports was colitis. Computed tomography of the abdomen showed a coil spring appearance mass about $9 \mathrm{~cm}$ in diameter in the left side of abdomen region Figures $1 \& 2$.

Colo-colic Intussusception was highly suspected. Second colonoscopy was done and it revealed a huge, ulcerative sub mucosal mass in the proximal portion of descending colon. Endoscopic biopsy was done and it showed a pattern of severe necrosis without evidence of malignancy. After review of above positive findings, surgical intervention was recommended. Midline laparatomy was performed; during exploration an Intussusception mass from splenic flexures to sigmoid colon was found Figure 3. An extended left hemicolectomy was done. Regional lymph node enlargement or invasion of surrounding structure was not observed. The histo pathologic examination confirmed a pedunculated Lipoma with chronic ulcer, measuring 9x5×6 cm in diameter Figure 4. After operation there, we have not any complication and patient was discharged on day five postoperative. Final pathologist report was Lipoma Figure 5.

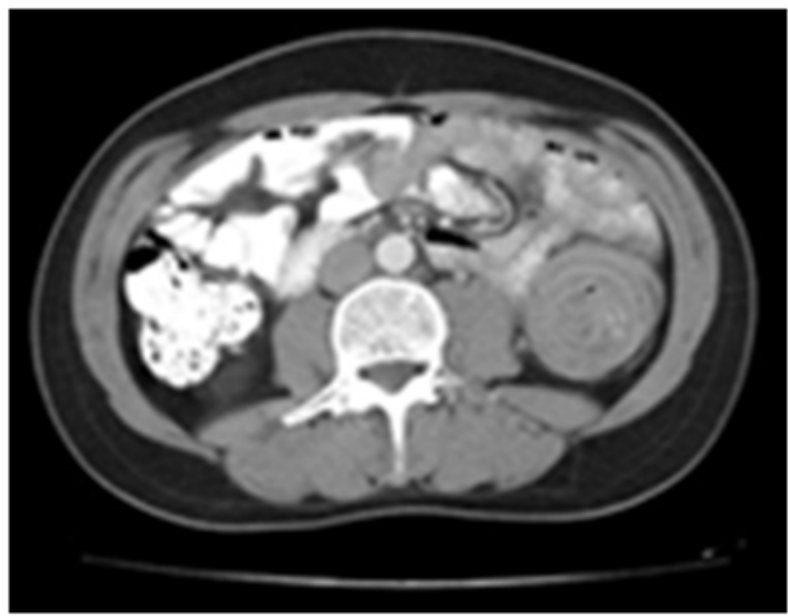

Figure I Computed tomography of the abdomen showed a coil spring appearance mass about $9 \mathrm{~cm}$ in diameter in the descending colon.

\section{Discussion}

Intussusception is a common condition in children that enlarged payer's patches are the most cause of it but in adult, Intussusception accounts for only $5 \%$ of all cases and $1 \%$ of all bowel obstructions. ${ }^{1}$ The most common sites of intussusceptions are entero-entric and ileocolic. ${ }^{2}$ In adult, almost always Intussusception is secondary to pathological intra luminal lesions. ${ }^{2}$ In two thirds of adult colo-colonic Intussusception primary colonic cancers has been detected. ${ }^{4}$ Peutz- 
Jehger polyps, adenomas, endometriosis, previous anastomosis and lipomasare the rest cause that should concern. ${ }^{3}$ Colicky abdominal pain, rectal bleeding and bowel obstructions are the most common symptoms and palpable mass can found in $24-42 \%$ of patients. ${ }^{4}$ CT scan is the most accurate radiological diagnosis study for intussusceptions but MRI, ultrasound and barium enema have also been the other investigations. ${ }^{5}$

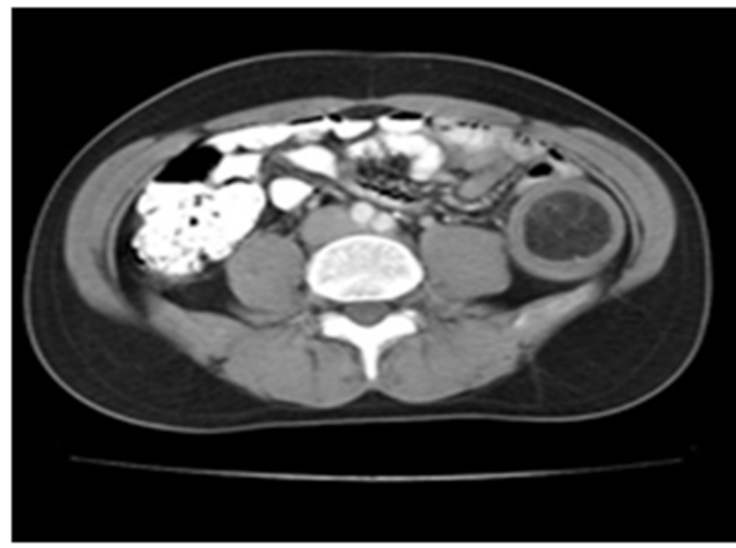

Figure 2 Computed tomography of the abdomen showed a soft tissue mas ( -40 till -120 Hounsfield units).

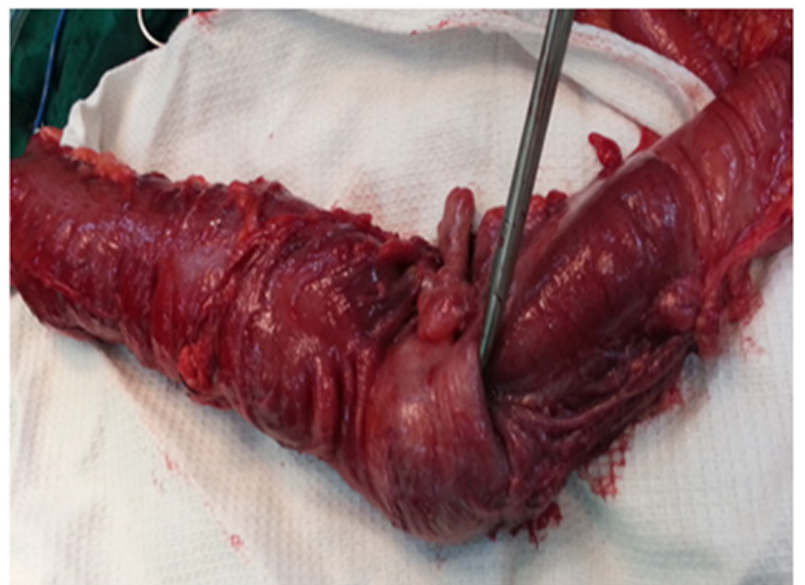

Figure 3 Shown sit of intussusception.

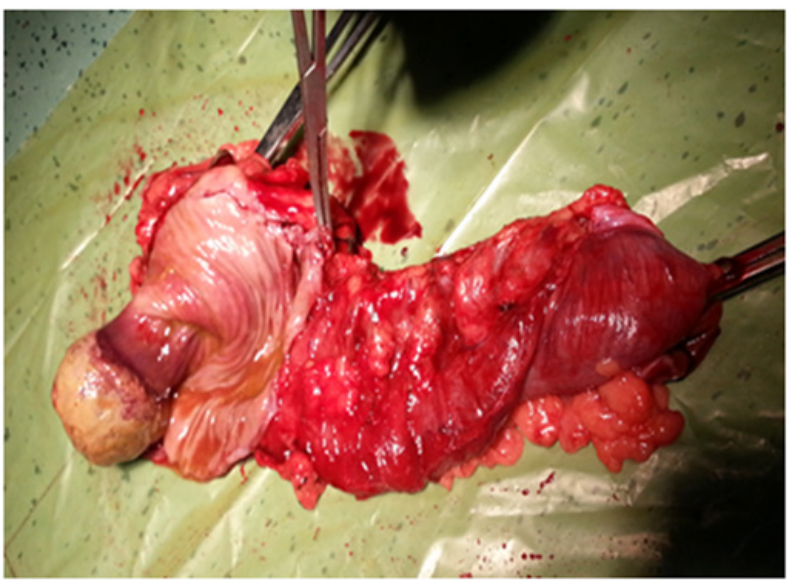

Figure 4 Shown pedunculatedlipoma of the intussusception sit.

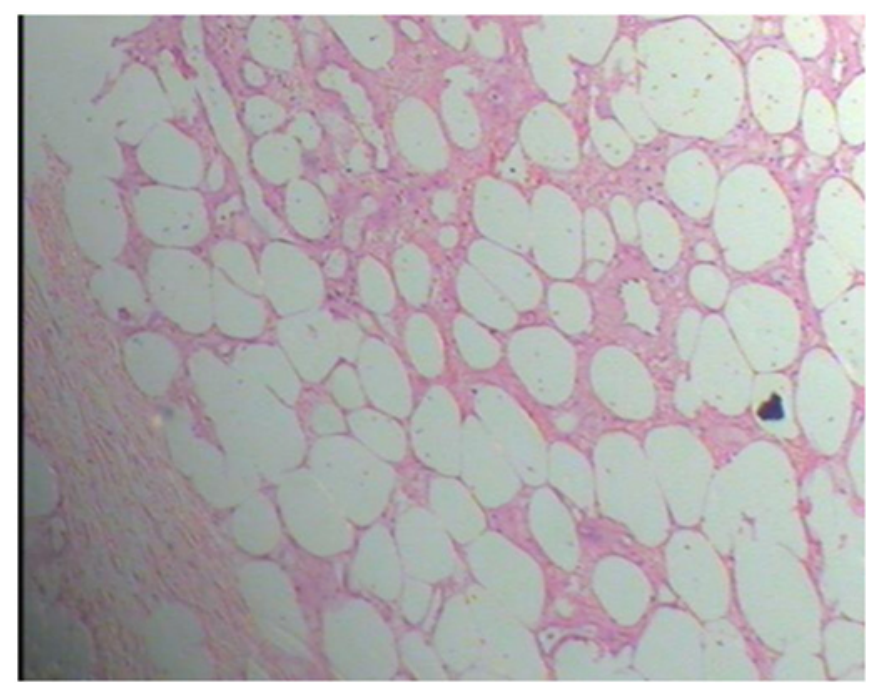

Figure 5 Pathology: sections show colonic wall tissue reveals a benign appearing neo formed lesion composed of proliferated bland-looking adipocytes with lobular growth pattern.

Colonic Lipoma can presented by abdominal pain, bleeding, constipation, perforation, bowel changes and Intussusception but in $94 \%$ of cases was asymptomatic and found incidentally during colonoscopy or surgical removed specimen. ${ }^{3,4,6}$ Diagnostic evaluations of colonic Lipoma such as barium enemas, CT scans and MRI could be complicated when Intussusception has been occurred and underlying fat necrosis can mimic malignant neoplasm's. ${ }^{5}$ In colonoscopy visualization, characteristic mark of Lipoma is elevated normal mucosa over the tumor and fat extrusion occurs after biopsy taking. ${ }^{3,4,5,7}$

Less than 50 cases of Lipoma to us Intussusception have been reported in the literatures and just 4 cases were involved cecumascending colon. ${ }^{3}$ Colonic Lipoma can be treated with different options, colonoscopy and surgical procedures. ${ }^{8,9}$ Endoscopic resection of Lipoma concerned for tumors less than $2 \mathrm{~cm}$, however perforation and hemorrhage can occurred during this procedure. ${ }^{4,8,9}$ Surgery has been recommended by many of the authors as the standard method of treatment for Lipoma greater than $2 \mathrm{~cm}$ in size., ${ }^{4,6,8,9}$ Surgical treatment includes resection, colotomy with local excision, limited colon resection, segmental resection, hemicolectomy, or subtotal colectomy; depends on the tumor size, location and presence of definitive diagnosis before operation, each kind of surgical methods that mentioned above can be used..$^{2-4,10}$ In our case we do extended left hemicolectomy. The choice procedure of colonic Intussusception is resection without reduction due to the underlying malignancy as we done. ${ }^{10}$

\section{Conclusion}

Large colonic Lipoma with symptoms should be excised either surgically or endoscopically. Small and pedunculated Lipoma $<4$ $\mathrm{cm}$ ) with normal tumor markers can undergo to endoscopic resection. Lipoma that are greater than $4 \mathrm{~cm}$ in size or in patients in whom malignancy cannot be ruled out should undergo segmental resection. ${ }^{4,9}$

\section{Funding}

None. 


\section{Acknowledgements}

None.

\section{Conflicts of interest}

The author declares that there is no conflict of interest.

\section{References}

1. Azar T, Berger DL. Adult intussusception. Ann Surg. 1997;226(2):134138.

2. Chiang JM, Lin YS. Tumor spectrum of adult intussusception. J Surg Oncol. 2008;98(6):444-447.

3. Paškauskas $\mathrm{S}$, Latkauskas T, Valeikaitė G, et al. Colonic intussusception caused by colonic lipoma: a case report. Medicina. 2010;46(7):477-481.

4. Jiang L, Jiang LS, Li FY, et al. Giant sub mucosal lipoma located in the descending colon: a case report and review of the literature. World $J$ Gastroenterol. 2007;13(42):5664-5667.
5. Pereira JM, Sirlin CB, Pinto PS, et al. CT and MR imaging of extrahepatic fatty masses of the abdomen and pelvis: techniques, diagnosis, differential diagnosis, and pitfalls. Radiographics. 2005;25(1):69-85.

6. Chiang JM, Lin YS. Tumor spectrum of adult intussusception. J Surg Oncol. 2008;98(6):444-447.

7. Tascilar O, Cakmak GK, Gün BD, et al. Clinical evaluation of submucosal colonic lipomas: decision making. World J Gastroenterol. 2006;12(31):5075-5077.

8. Ladurner R, Mussack T, Hohenbleicher F, et al. Laparoscopic-assisted resection of giant sigmoid lipoma under colonoscopic guidance. Surg Endosc. 2003;17(1):160.

9. Peters MB, Obermeyer RJ, Ojeda HF, et al. Laparoscopic management of colonic lipomas: a case report and review of the literature. JSLS 2005;9(3):342-344.

10. Croome KP, Colquhoun PH. Intussusception in adult. Can J Surg. 2007;50(6): E13-E14. 